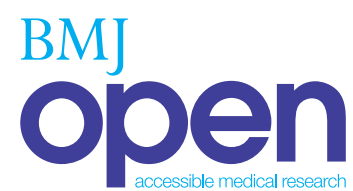

\title{
Health service use in adults 20-64 years with traumatic brain injury, spinal cord injury or pelvic fracture. A cohort study with 9-year follow-up
}

To cite: Laursen B, HelwegLarsen $\mathrm{K}$. Health service use in adults 20-64 years with traumatic brain injury, spinal cord injury or pelvic fracture. A cohort study with 9-year follow-up. BMJ Open 2012;2: e001521. doi:10.1136/ bmjopen-2012-001521

- Prepublication history and additional material for this paper are available online. To view these files please visit the journal online (http://dx.doi.org/10.1136/ bmjopen-2012-001521).

Received 28 June 2012 Accepted 26 September 2012

This final article is available for use under the terms of the Creative Commons Attribution Non-Commercial 2.0 Licence; see http://bmjopen.bmj.com

\author{
Bjarne Laursen, Karin Helweg-Larsen
}

\section{ABSTRACT}

Objectives: To estimate the health service use over 9 years after the injury year for patients with traumatic brain injury (TBI), spinal cord injury (SCI) and pelvic fracture (PF), and compare with non-injured.

Design: A register-based cohort design with a 9-year follow-up period.

Setting: The Danish population.

Participants: The study included 434, 100 and 278 hospital-treated incident patients with $\mathrm{TBI}, \mathrm{SCl}$ and $\mathrm{PF}$, respectively, among 20-year-olds to 64-year-olds identified using the National Patient Register. Controls for each patient group were drawn from the population register, matched by age, sex and health service use during 1995. All were followed during 1996-2005 by linkage to national health registers. The observations were excluded when the patients left Denmark or died.

Outcome measures: The use of hospital treatments, contacts with general practitioners and the use of physiotherapy.

Results: Compared to the controls, more patients with $\mathrm{TBI}$ and $\mathrm{SCI}$ were hospital admitted all 9 years after the injury year, on average 0.36 and 0.50 times annually, respectively. For patients with PF hospital admissions returned to baseline year 2 after the injury year. For patients with $\mathrm{SCl}$ the use of general practitioner services remained at an increased level year 9 after the injury year, while it returned to baseline level year 4 after the injury year for patients with TBI and year 2 for patients with PF. For patients with SCI physiotherapy use remained increased over 9 years after the injury year, while it returned to baseline the fifth year for patients with TBI and the third year after for patients with PF.

Conclusions: $\mathrm{TBI}$ and $\mathrm{SCl}$ increase the use of health services over 9 years after the injury year, while most health service use after PF returned to baseline 2 years after the injury year.

\section{INTRODUCTION}

Injury patients may have disabilities and pain complaints for years ${ }^{1-4}$ resulting in a high use of health services many years after the injury. Three injury groups are important

\section{ARTICLE SUMMARY}

\section{Article focus}

The focus of this article is on the use of health services after injury:

- Frequency of hospital treatments.

- Frequency of general practitioner use.

- Frequency of physical therapy.

Key messages

- Patients with traumatic brain injury or spinal cord injury had an increased health service use all 9 year after the injury.

- For patients with pelvic fracture the health service use approached the baseline level 2 years after the injury.

Strengths and limitations of this study

- Being a study based on national registers there is almost complete follow-up.

- The patients were compared with matched control groups.

- Case identification may be inaccurate because the patient register is an administrative register.

- Reporting of health service use may have changed during the follow-up period.

due to their severity and long-term effects: traumatic brain injury (TBI), spinal cord injury (SCI) and pelvic fracture (PF). Depending on the spinal cord level of the injury, SCI may cause permanent paralysis and consequently other somatic health problems. Hence, the demand for health services among patients with SCI is generally high. ${ }^{5}$ In high-income countries, TBI is a leading cause of mortality and disability among young individuals, ${ }^{6}$ and often causes permanent disabilities. ${ }^{7}$ Patients with PFs have a high mortality, ${ }^{8}$ and $\mathrm{PF}$ may result in chronic health problems. ${ }^{9}$

Previously, a number of studies have reported the long-term effect of severe injuries as measured by the use of health services. $^{5}{ }^{10-12}$ However, most studies only
Dr Bjarne Laursen;

bla@niph.dk, bjla@sdu.dk 
include data on healthcare contacts up to 1 year after the injury, with the exception of two studies that analyse the long-term consequences of SCI. ${ }^{5}{ }^{13}$ The Danish National Health Registers enable us to identify patients with TBI, SCI and PF, and to conduct a long-term follow-up of their health service use compared to a matched reference group of non-injured. The purpose of the present study was, thus, to provide further knowledge of the burden of these three types of severe injuries as measured by hospital contacts and use of primary healthcare services.

\section{METHODS}

The study is based on a cohort design using register information to identify cases and the health service use over a 9-year follow-up period. The population studied were Danish residents during the year 1996. Patients with TBI, SCI and PF were identified using the Danish National Patient Register. ${ }^{14}$ The register contains information on all contacts with Danish hospitals, including hospital admissions, emergency department contacts and other outpatient treatments from 1995 onwards.

Three categories of severe traumatic injury were included, TBI (ICD-10 diagnoses S06.1-S06.9), SCI (S14.0-1, S24.0-1, S34.0-1, S34.3, T06.1, T09.3), and PF (S32.3-8). Cases were identified in the National Patient Register 1996 as 20-64-year-olds with one of these specific diagnoses and registered as a new patient, either as hospital admitted or treated at an emergency department. Patients who died immediately after the injury are typically not registered with an injury diagnosis and are therefore not included. In order to include only incident cases, persons registered in the National Patient Register 1978-1995 with one or more of these diagnoses were excluded from each case group. Patients were also excluded if they were hospital treated for other injuries during 1996 that may cause lifelong disability. ${ }^{15}$ For each of the three case groups controls were selected randomly from the Danish population at baseline (1995), matched by 10 years age groups, gender and health service use during the year 1995 (hospital admission, yes or no; outpatient treatment at a hospital, yes or no; use of general practitioner $(0-1,2-4,5-9,10-19,20+$ services); use of physiotherapy, yes or no). The use of 1995 for the year of matching was to avoid bias. Four controls were selected randomly for each case. This may result in a possible overlap between the three control groups.

All data about health service use are registered using the unique person number that makes it possible to obtain information about health service use in the study and control groups during the whole period. Information on health service use was retrieved from the National Patient Register and the National Health Service Register. ${ }^{16}$ The outcomes were for each of the calendar years 1995-2005: number of hospital admissions; number of treatment days as hospital outpatient; number of services from general practitioners (GP); number of treatment by physiotherapists. The number of GP services may be higher than the number of contacts, as several services may be offered during a single contact (eg, blood tests). Information on migration and mortality was obtained from Statistics Denmark and the Cause of Death Register. Except for 1996 observation years for patients and controls were excluded if the patient died or emigrated during or before the year. The amount of health service use was divided by the number of observation years.

For each of the years 1996-2005, in the following called years $0-9$, the use of health services for cases was compared to the controls using the Mann-WhitneyWilcoxon rank sum test (PROC Nparlway, SAS V.9.2).

Table 1 Mean number of hospital admissions from years -1 to 9 among patients compared with controls

\begin{tabular}{|c|c|c|c|}
\hline \multirow[b]{2}{*}{ Year } & \multicolumn{3}{|c|}{ Number of admissions among cases; and controls } \\
\hline & $\begin{array}{l}\text { Brain injury ( } n=434 \text { at } \\
\text { baseline) }\end{array}$ & $\begin{array}{l}\text { Spinal cord injury ( } \mathrm{n}=100 \text { at } \\
\text { baseline) }\end{array}$ & $\begin{array}{l}\text { Pelvic fracture }(n=278 \text { at } \\
\text { baseline) }\end{array}$ \\
\hline-1 & $0.23 ; 0.19$ & $0.38 ; 0.27$ & $0.33 ; 0.25$ \\
\hline 0 & $2.18 ; 0.16^{\star \star \star}$ & $1.60 ; 0.18^{\star \star \star}$ & $1.37 ; 0.20^{\star \star \star}$ \\
\hline+1 & $0.55 ; 0.17^{\star \star \star}$ & $0.94 ; 0.16^{\star \star \star}$ & $0.49 ; 0.17^{\star \star \star}$ \\
\hline+2 & $0.28 ; 0.18^{\star}$ & $0.46 ; 0.16^{\star \star \star}$ & $0.32 ; 0.21$ \\
\hline+3 & $0.30 ; 0.21^{*}$ & $0.44 ; 0.16^{*}$ & $0.20 ; 0.22$ \\
\hline+4 & $0.29 ; 0.19^{\star \star}$ & $0.38 ; 0.17^{*}$ & $0.33 ; 0.22$ \\
\hline+5 & $0.22 ; 0.20$ & $0.25 ; 0.13$ & $0.37 ; 0.21^{*}$ \\
\hline+6 & $0.25 ; 0.24$ & $0.56 ; 0.14^{\star \star *}$ & $0.36 ; 0.18$ \\
\hline+7 & $0.32 ; 0.24^{*}$ & $0.45 ; 0.13^{\star \star \star}$ & $0.32 ; 0.19$ \\
\hline+8 & $0.28 ; 0.25^{*}$ & $0.48 ; 0.17^{\star *}$ & $0.25 ; 0.25$ \\
\hline+9 & $0.29 ; 0.24^{*}$ & $0.61 ; 0.14^{\star \star}$ & $0.27 ; 0.24$ \\
\hline $\begin{array}{l}\text { Mean per year, year } \\
1-9\end{array}$ & $0.36 ; 0.23^{\star \star \star}$ & $0.50 ; 0.15^{\star \star \star}$ & $0.42 ; 0.23^{\star \star \star}$ \\
\hline
\end{tabular}


The purpose of the tests was to determine whether the observed differences between the cases and control groups could be due to chance.

\section{RESULTS}

\section{Traumatic brain injury}

According to the National Patient Register 1996, a total of 480 persons were treated at a hospital with a diagnosis of TBI and recorded as incident cases. When removing patients treated for TBI the previous years, 434 were found to be real incident cases and included in the study. Of these, 313 (72\%) were admitted for more than 1 day. Their mean age (SD) was 41 (13) years and $70 \%$ were men. Nearly half of the injuries (181) were road traffic injuries, mostly as car drivers or passengers $(n=76)$ or bicyclists $(n=60)$. Forty-two were workplace injuries, 24 were caused by interpersonal violence and 15 were sports injuries. About one-quarter (102) occurred at home. Of the non-traffic injuries 151 were due to falls, half of these from a higher level. Of the falls 60 occurred at home, 21 during paid work and 7 when performing sports. The most common ICD-10 diagnoses were S06.2 (diffuse TBI, $\mathrm{n}=190$ ), and S06.5 (traumatic subdural haemorrhage, $\mathrm{n}=86$ ). During the follow-up time 127 died, of these 89 during 1996. Thirteen left Denmark during the follow-up period. Among the 1736 controls 116 died and 55 left Denmark or were not found in the population register. The mean follow-up time was 7 years for the cases and 8.9 years for the controls. Eight of the controls were common to the PF controls, and two were common to the SCI controls. After the injury year, the mortality in the injured group was 0.013 year, which is higher than the 0.008 /year in the reference group $(p=0.003)$. Compared to the controls, patients with TBI were significantly more often admitted to hospital years 1-9 after the injury year (table 1), and more often treated as outpatients years 1-6 after the injury year (table 2). The number of GP services was increased years 1-3 after the injury year (table 3). The use of physiotherapy was larger compared to the controls years 1-4 and 8-9 after the injury year (table 4). During the years 1-9 patients with TBI were on average annually admitted 0.36 times, treated as outpatients 3.54 days, had 8.23 GP services, and were treated by physiotherapists 9.2 times.

\section{Spinal cord injury}

In 1996, a total of 157 persons were treated at a hospital due to SCI and registered as incident cases. When removing patients treated for SCI the previous years, 100 were found to be real incident cases and included in the study. Their mean age (SD) was 34 (11) years and 69\% were men. Nearly half of the injuries $(n=48)$ were road traffic injuries, mostly as car drivers or passengers $(n=26)$. Eleven were workplace injuries, seven were sports injuries, and violence caused six of the injuries. Nineteen injuries occurred at home. Twenty of the nontraffic injuries were due to falls; half of these were from a higher level. Of the falls nine occurred at home, four during paid work and four when performing sports. The most common ICD-10 diagnoses were S14.1 (injuries of cervical spinal cord, $\mathrm{n}=55$ ) and S24.1 (injuries of thoracic spinal cord, $n=21$ ). During the follow-up time three died, none during the injury year. Four left Denmark or were not found in population registers. Among the controls 10 died, and 22 left Denmark or were not found. The mean follow-up time was 9.2 years in the case group and 9.1 years in the control group. Two of the controls were common to the TBI controls, and one was common to the PF controls. The mean mortality during years $1-9$ was 0.003 /year in both the case and the control group. Throughout the follow-up period patients with SCI were more hospital treated as inpatient or outpatient compared to the control group, with the exception of year 5 for all treatments and years 5 and 8 for outpatient treatments (tables 1 and 2). The

Table 2 Mean number of outpatient treatment days from years -1 to 9 among patients compared with controls

\begin{tabular}{|c|c|c|c|}
\hline \multirow[b]{2}{*}{ Year } & \multicolumn{3}{|c|}{ Number of treatment days among cases; and controls } \\
\hline & Brain injury & Spinal cord injury & Pelvic fracture \\
\hline-1 & $0.71 ; 0.69$ & $0.88 ; 1.05$ & $0.69 ; 0.88$ \\
\hline 0 & $1.98 ; 0.79^{\star \star \star}$ & $0.92 ; 1.08^{\star *}$ & $1.79 ; 0.92^{\star * *}$ \\
\hline+1 & $3.00 ; 0.89^{\star * *}$ & $1.47 ; 0.86^{\star * *}$ & $2.12 ; 1.03^{\star * \star}$ \\
\hline+2 & $2.96 ; 0.98^{\star \star \star}$ & $1.50 ; 1.01^{\star \star \star}$ & $1.33 ; 1.01^{\star \star \star}$ \\
\hline+3 & $1.80 ; 1.24^{\star \star}$ & $1.76 ; 1.00^{\star \star \star}$ & $1.26 ; 1.19^{*}$ \\
\hline+4 & $1.47 ; 1.41^{*}$ & $2.01 ; 1.60^{\star *}$ & $1.44 ; 1.21^{\star *}$ \\
\hline+5 & $1.86 ; 1.34$ & $1.67 ; 2.22$ & $1.91 ; 1.26^{\star}$ \\
\hline+6 & $2.03 ; 1.46^{\star \star}$ & $1.89 ; 1.19^{\star \star}$ & $1.69 ; 1.50^{\star}$ \\
\hline+7 & $2.83 ; 1.83^{\star}$ & $1.86 ; 1.62^{\star *}$ & $1.86 ; 2.12^{*}$ \\
\hline+8 & $2.02 ; 1.49$ & $2.08 ; 1.31$ & $2.49 ; 1.53$ \\
\hline+9 & $1.93 ; 1.61$ & $2.37 ; 1.12^{\star \star \star}$ & $1.61 ; 1.60$ \\
\hline Mean per year, year $1-9$ & $2.20 ; 1.41^{\star * *}$ & $1.79 ; 1.34^{* * *}$ & $1.87 ; 1.43^{\star \star \star}$ \\
\hline
\end{tabular}

Year 0 is the injury year (1996).

${ }^{\star}$ Significantly more treated than matched controls $(p<0.05) .{ }^{* *} p<0.01,{ }^{* * *} p<0.001$ 
Table 3 Mean number of GP services from years -1 to 9 among patients compared with controls

\begin{tabular}{|c|c|c|c|}
\hline \multirow[b]{2}{*}{ Year } & \multicolumn{3}{|c|}{ Number of GP services among cases ; and controls } \\
\hline & Brain injury & Spinal cord injury & Pelvic fracture \\
\hline-1 & $7.31 ; 7.24$ & $6.60 ; 7.72$ & $7.36 ; 7.27$ \\
\hline 0 & $8.55 ; 6.59^{\star \star \star}$ & $8.49 ; 6.99^{\star * *}$ & $10.21 ; 6.56^{\star \star \star}$ \\
\hline+1 & $8.62 ; 6.48^{\star \star \star}$ & $9.31 ; 6.68^{\star \star \star}$ & $9.67 ; 6.94^{\star \star \star}$ \\
\hline+2 & $8.44 ; 6.63^{\star \star \star}$ & $10.02 ; 7.26^{\star \star \star}$ & $9.06 ; 7.13$ \\
\hline+3 & $7.80 ; 7.04^{*}$ & $9.94 ; 7.15^{\star *}$ & $8.40 ; 7.07$ \\
\hline+4 & $7.81 ; 7.19$ & $9.84 ; 7.09^{*}$ & $8.93 ; 7.47$ \\
\hline+5 & $7.70 ; 7.51$ & $9.47 ; 7.10^{* *}$ & $8.55 ; 7.36$ \\
\hline+6 & $8.04 ; 7.43$ & $10.97 ; 6.92^{\star \star \star}$ & $9.60 ; 7.50$ \\
\hline+7 & $7.60 ; 7.87$ & $9.50 ; 7.29^{\star}$ & $9.97 ; 7.70$ \\
\hline+8 & $7.89 ; 8.05$ & $10.40 ; 7.77^{\star \star}$ & $9.61 ; 8.33$ \\
\hline+9 & $8.11 ; 8.15$ & $11.19 ; 8.30^{\star *}$ & $10.15 ; 8.50$ \\
\hline Mean per year, year $1-9$ & $8.23 ; 7.54^{\star \star}$ & $9.94 ; 7.31^{\star \star \star}$ & $9.90 ; 7.72^{*}$ \\
\hline
\end{tabular}

number of GP services was increased throughout the follow-up period, and so was the physiotherapy use (table 3). During the years 1-9 patients with SCI were on average annually admitted 0.50 times, treated as outpatients 2.97 days, had 9.9 GP services, and 18.3 treatments by physiotherapists.

\section{Pelvic fracture}

In 1996, a total of 286 persons were hospital treated due to $\mathrm{PF}$ and registered as incident cases. Where removing patients treated for PF the previous years, 278 were real incident cases and included in the study. Their mean age (SD) was 43 (12) years and 52\% were men. About one-third of the injuries $(n=104)$ were road traffic injuries, mostly as car drivers or passengers $(n=55)$ or bicyclists $(n=25)$. Thirty-two were workplace injuries, 30 were sports injuries and violence caused one of the injuries. Eighty-eight injuries occurred at home. Of the nontraffic injuries 128 were due to falls, 73 from a higher level. Sixty-six falls occurred at home, 15 during paid work and 11 when performing sports. The most frequent ICD-10 diagnoses were S32.5 (fracture of pubis, $\mathrm{n}=122$ ) and S32.8 (fracture of other and unspecified parts of lumbar spine and pelvis, $n=94$ ). During the follow-up time 48 died, of these 10 during the injury year. Eight persons left Denmark or were not part of the population register for other reasons. In the control group 68 died and 30 left Denmark or the population register. The mean follow-up time was 8.1 year for the cases and 9.1 years for the controls. Eight of the controls were common to the TBI controls, and one was control to the patients with SCI. During the years 1-9 the injured group had a higher mortality $(0.017 /$ year $)$ compared to the reference group $(0.007 /$ year, $\mathrm{p}<0.0001)$. The excess mortality occurred mostly during the first 3 years after the injury year. Compared to the controls, patients with PF were significantly more treated as outpatients the years 1-7 after the injury year (table 2), and

Table 4 Mean number of treatments by physiotherapists from years -1 to 9 among patients compared with controls

\begin{tabular}{|c|c|c|c|}
\hline \multirow[b]{2}{*}{ Year } & \multicolumn{3}{|c|}{ Number of treatments among cases; and controls } \\
\hline & Brain injury & Spinal cord injury & Pelvic fracture \\
\hline-1 & $1.28 ; 2.47$ & $11.03 ; 5.31$ & $3.84 ; 2.00$ \\
\hline 0 & $4.27 ; 2.61^{\star \star \star}$ & $15.49 ; 6.73^{\star *}$ & $8.29 ; 2.63^{\star \star *}$ \\
\hline+1 & $8.83 ; 2.66^{\star \star *}$ & $27.21 ; 4.10^{\star \star *}$ & $12.68 ; 2.72^{\star \star \star}$ \\
\hline+2 & $13.10 ; 3.20^{* * *}$ & $27.72 ; 4.47^{\star * *}$ & $10.96 ; 2.50^{\star \star}$ \\
\hline+3 & $14.29 ; 3.58^{\star \star \star}$ & $20.49 ; 5.00^{\star \star *}$ & $8.47 ; 2.58$ \\
\hline+4 & $12.93 ; 3.93^{\star \star \star}$ & $19.74 ; 5.44^{\star}$ & $8.38 ; 3.25$ \\
\hline+5 & $8.94 ; 3.32$ & $16.01 ; 3.54^{\star *}$ & $6.17 ; 2.03$ \\
\hline+6 & $5.04 ; 2.27$ & $12.41 ; 1.63^{\star \star *}$ & $2.67 ; 1.20$ \\
\hline+7 & $4.93 ; 2.11$ & $12.50 ; 1.57^{\star \star \star}$ & $2.18 ; 1.52$ \\
\hline+8 & $5.99 ; 2.05^{\star \star}$ & $13.30 ; 1.74^{\star \star *}$ & $2.09 ; 1.71$ \\
\hline+9 & $5.96 ; 2.33^{\star}$ & $13.23 ; 1.45^{\star * *}$ & $2.59 ; 1.75$ \\
\hline Mean per year, year 1-9 & $9.21 ; 2.87^{\star \star \star}$ & $18.29 ; 3.18^{\star \star \star}$ & $6.20 ; 2.12^{\star \star}$ \\
\hline
\end{tabular}


had a higher GP service only the year after the injury year (table 3). The use of physiotherapy was increased the years 1 and 2 after the injury year (table 4). During the years 1-9 patients with PF were on average annually admitted 0.42 times, treated as outpatients 3.52 days, had 9.9 GP services, and were treated 6.2 times by physiotherapists.

\section{Comparison of injury types}

For the mean health service use during the years 1-9 only few differences were found between the three injury types. Patients with SCI were more often admitted than were the patients with TBI and PF. Further, patients with SCI had a considerably larger use of physiotherapy than had patients with TBI and PF. There were no differences in the mean use of GP services and of outpatient treatments between the three patient groups.

\section{DISCUSSION}

The present study is based on a well-defined study and reference population identified by register data that cover the total adult population. The national health registers include data about hospital contacts and use of primary healthcare services. ${ }^{17}$ Contacts with private hospitals may not be included in the national patient register; however, these contacts only contribute less than 3\% of the total number of outpatient contacts and $1 \%$ of all admissions. ${ }^{18}$ All data about health service use are registered using the unique person number that made it possible to obtain information about health service use in the study and control groups during the follow-up period.

Patients with the three studied types of injury had an increased use of health services compared to a matched reference group during the follow-up period. However, the amount, duration and type of health service use differed between the types of injury. Patients with SCI had the highest use of health services, about three times more admissions and six times more physiotherapy use compared to the controls. The level of use remained that high 9 years after the injury year. For patients with TBI the number of hospital admissions was increased most of the 9 years after the injury year, while outpatient treatments and the use of GP services approached the baseline level year 4 after the injury year. For patients with PF the health service use approached baseline level year 2 after the injury year; although not significant, the use of physiotherapy among patients with PF was above baseline level 5 years after the injury year.

Our results concern the age-group of 20-year-olds to 64-year-olds, whereas several previous studies of health service use after severe traumatic injuries include either older or younger age-groups, hence, results are not directly comparable. A Canadian study of SCI included patients 70 years old and above, and reported a higher contact rate to physicians 1 year after the injury year than did our study, ${ }^{11}$ and a study by Becker $e t a l^{10}$ of PF patients based on US Medicare data and thus including mainly older patients reported a higher use of GP services 6 months postinjury than our study. However, the frequency of hospital admission among patients with SCI in our study is comparable to a Canadian study that followed 223 SCI patients 6 years postinjury. ${ }^{5}$

A US study of healthcare use among paediatric patients with TBI reported about the same level of physiotherapy use as we observed among 20-year-olds to 64-year-olds in our study but found a lower rate of GP contacts. ${ }^{19}$ In accordance with our results few studies report long lasting increase in the use of health services after $\mathrm{PF}^{20}$

The level of healthcare use may depend on the healthcare system. In Denmark most treatments are free of charge or only partly paid by the patient. Further, different services are included. For example, physiotherapy may include both individual treatments and training in a group. This may be part of the explanation to the relatively frequent use of, for example, physiotherapy.

There are, however, some limitations to the present study. The case identification is based on the National Hospital Register and, thus, depends on the validity of this register. In general, the data in the National Hospital Register are found to be valid, however depending on diagnosis; about $79 \%$ of the injury diagnoses were correct. ${ }^{17}$ In the present study, we included diagnoses that were not specific, like S32.8, fracture of other and unspecified parts of lumbar spine and pelvis. This limited the possibility to study more specific injury groups. Because the study is based on administrative data reporting of services may change during the period, the numbers should be interpreted with care. In some cases a few persons uses a relatively large part of the services.

Patients treated during 1996 for other injuries with lifelong consequences according to Haagsma $e a^{15}$ were excluded from the study. This may result in underestimation of the effect of the injury.

In order to solely include incident cases in 1996, we excluded cases registered with the same or similar diagnoses during 1978-1995. However, some of the patients treated in 1996 may have been injured before 1978 and not treated during the period 1978-1995. This may result in a larger health service use in the patient group at baseline. Due to the matching by health service use there may also be a larger health service use in the control group.

\section{CONCLUSION}

TBI and SCI increased the use of health services over a period of 9 years after the injury year, while most of the health service use after PF returned to baseline 2 years after the injury year.

Contributors BL contributed to the conception and design, performing the analyses, writing the manuscript and the final approval. $\mathrm{KH}-\mathrm{L}$ contributed to the conception and design, writing the manuscript and the final approval. 
Funding This work was supported by TrygFonden, grant no. 7585-07.

Competing interests None.

Ethics approval The access to the data was approved by Statistic Denmark. Being a study based on existing register data approval from the Ethics Committee and from the Data Protection Agency was not needed.

Data sharing statement There are no unpublished data available.

\section{REFERENCES}

1. Dijkers MP. Quality of life after traumatic brain injury: a review of research approaches and findings. Arch Phys Med Rehabil 2004;85 (4 Suppl 2):S21-35.

2. Toft AM, Moller H, Laursen B. The years after an injury: long-term consequences of injury on self-rated health. $J$ Trauma 2010;69:26-30.

3. Braithwaite IJ, Boot DA, Patterson M, et al. Disability after severe injury: five year follow up of a large cohort. Injury 1998;29:55-9.

4. Polinder S, van Beeck EF, Essink-Bot ML, et al. Functional outcome at 2.5, 5, 9, and 24 months after injury in the Netherlands. $J$ Trauma 2007;62:133-41.

5. Dryden DM, Saunders LD, Rowe BH, et al. Utilization of health services following spinal cord injury: a 6-year follow-up study. Spinal Cord 2004:42:513-25.

6. Maas Al, Stocchetti N, Bullock R. Moderate and severe traumatic brain injury in adults. Lancet Neurol 2008;7:728-41.

7. Wrona RM. Disability and return to work outcomes after traumatic brain injury: results from the Washington State Industrial Insurance Fund. Disabil Rehabil 2010;32:650-5.

8. Naam NH, Brown WH, Hurd R, et al. Major pelvic fractures. Arch Surg 1983;118:610-16.
9. Borg $\mathrm{T}$, Berg $\mathrm{P}$, Fugl-Meyer $\mathrm{K}$, et al. Health-related quality of life and life satisfaction in patients following surgically treated pelvic ring fractures. A prospective observational study with two years follow-up. Injury 2010;41:400-4.

10. Becker DJ, Yun H, Kilgore ML, et al. Health services utilization after fractures: evidence from Medicare. J Gerontol A Biol Sci Med Sci 2010;65:1012-20.

11. Munce SE, Guilcher SJ, Couris CM, et al. Physician utilization among adults with traumatic spinal cord injury in Ontario: a population-based study. Spinal Cord 2009;47:470-6.

12. Guilcher SJ, Munce SE, Couris CM, et al. Health care utilization in non-traumatic and traumatic spinal cord injury: a population-based study. Spinal Cord 2010;48:45-50.

13. Hall KM, Knudsen ST, Wright J, et al. Follow-up study of individuals with high tetraplegia (C1-C4) 14 to 24 years postinjury. Arch Phys Med Rehabil 1999;80:1507-13.

14. Lynge E, Sandegaard JL, Rebolj M. The danish national patient register. Scand J Public Health 2011;39(7 Suppl):30-3.

15. Haagsma JA, Polinder S, Lyons RA, et al. Improved and standardized method for assessing years lived with disability after injury. Bull World Health Organ 2012;90:513-21.

16. Sahl AJ, De Fine ON, Krasnik A. The danish national health service register. Scand J Public Health 2011;39(7 Suppl):34-7.

17. Nickelsen TN. Data validity and coverage in the Danish National Health Registry. A literature review. Ugeskr Læger 2001;164:33-7.

18. National Board of Health, Denmark. (Activity at hospitals. Public and private)www.sst.dk/Indberetning\%20og\%20statistik/Sundhedsdata/ Behandling ved sygehuse/DSNO.aspx(accessed10 Sep 2011).

19. Slomine BS, McCarthy ML, Ding R, et al. Health care utilization and needs after pediatric traumatic brain injury. Pediatrics 2006;117: e663-74.

20. Kiely N, Williams N. Sexual dysfunction in women following pelvic fractures with sacro-iliac disruption. Injury 1996;27:45-6. 